\title{
The Implementation of Industrialized Building System (IBS) in Iran Construction Companies
}

\author{
MiladSamari * NarimanGhodrati* \\ MohdWiraMohdBin Shafiei \\ School of Housing, Building and Planning, UniversitiSains Malaysia (USM), 11800 Penang Malaysia
}

\begin{abstract}
Industrialized Building System (IBS) is the new method of constructing building in the construction industry as a solution to improve construction image and performance. However this concept is generally accepted and applied in developed countries and some developing countries as well, does not have appropriate position in the construction industry in Iran. Most of construction companies in Iran still consist on conventional method instead of using IBS. This paper is attempting to find out the benefits and problems of applying IBS in construction projects, to identify the easiness of IBS usage for construction companies, to explore level of usefulness of IBS for Iranian construction companies and finally to recommend some solutions to promote IBS concept in developing countries. To collect data for this study, a questionnaire survey was conducted among the construction companies in Iran. A total of 827 questionnaires were sent out through mail and 117 of them answered. The respondent rate was $14.1 \%$. It was perceived that, there is an acceptable range of knowledge on IBS among the construction professionals, but the level of the IBS implementation in construction projects was extremely low. Because higher cost, lack of expertise and lack of supportive rules and regulations.
\end{abstract}

Keywords:Industrialized Building System, Construction, Benefits of IBS, Barriers, Iran

\section{INTRODUCTION}

The construction industry of Iran has been experiencing a turnaround since 2005 and is thought to grow $6.86 \%$ yearonyear (y-o-y) in 2007. In spite of the United Nation's (UN) sanctions on Iran, foreign investments in the country have not reduced, contemplating well on its business potential. Industrial construction displays powerful growth potential. This report predicts the industry is probably to be valued at $\$ 13.10 \mathrm{bn}$ in 2008 , and it registers an average growth of $4.40 \%$ over 2008-2012. Urged by its necessity to enhance its infrastructure in order to reach the fundamental global standards, and the necessity to provide housing to its burgeoning population, the construction industry of Iran will go on enhancing in the medium term. BMI foretells the industry to be valued at $\$ 26.40$ billion by 2012 (Iran Annual Report, 2008).

In the $20^{\text {st }}$ century, Industrialized Building System (IBS) is the new method of constructing building in the construction industry as a solution to improve construction image and performance (Kamar, 2009).Chung\&Kadir (2007) define IBS as a mass production of construction components in the factory or at the sitebase ondetailed planwith standard dimensions and transport to the site.IBS is also defined as "an integrated manufacturing and construction process with well-planned organization for efficient management, preparation and control over the resources used, activities and results supported by highly developed components" (Lessing, et al., 2005).

\section{BENEFITS OF USING IBS METHOD IN THE CONSTRUCTION INDUSTRY}

Many studies have been conducted to compare the industrialized building system method with conventional construction method. Using the IBS method in the construction industry will enable to:

Table1. Benefits of IBS

\begin{tabular}{|c|c|c|}
\hline Subject & $\begin{array}{c}\text { Benefit } \\
\end{array}$ & References \\
\hline Time & $\begin{array}{l}\text { Prefabrication takes place at a centralized factory } \\
\text { Casting of precast element at factory } \\
\text { Provides earlier occupation of the building }\end{array}$ & Peng, 1986 \\
\hline Cost & $\begin{array}{l}\text { Reducing interest payment } \\
\text { Capital outlays } \\
\text { Lower total construction costs } \\
\text { The repetitive using system formwork and scaffolding }\end{array}$ & Bing et al. 2001 \\
\hline Quality & Quality improvement through the construction standardization & Warszawski, 1999 \\
\hline
\end{tabular}


Flexibility in architectural design

Minimize the monotony of repetitive facades

Flexibility in the design of precast element

Zaini, 2000

Produce unique prefabrication construction methods

Reduction of labor intensity

Safety Reducingthe labor requirementon site.

Warszawski, 1999

Usethe high degree of mechanization

Minimal wastage, less site materials

Environment Construction operation is not affected by the adverse weather condition(build in the factory)

\section{ESSENTIAL CHARACTERISTICS NEED FOR IMPLEMENTATION IBS}

For developing and implementation IBS method in the construction industry, the superior construction technology requireshighly skilled workers. The government should establish new rules and regulation to support the IBS. For this purpose the government must prepare a training course for professionals and construction workers.To hold training classessuch as system Integrator, assemblers and apprenticeship for professional and construction workers more time and investment is required (Thanoonet al. 2003, IBS Steering Committee, 2006, Rahman\& Omar, 2006).

According to the research conducted by Hamid et al (2008), lack of past experience and technical knowledge of professionals in Malaysia is one of the most important obstacles existed against developing IBS.Their finding show that the lack of research and development, low IT adoption and shortage lack of technology have generally discouraged the private and public construction companies to use the IBS method in the projects.

It is clear that using this method in the projects at the first stepcreate difficulty for the contractors and construction companies. Because using special materials and import high technology based on the current situation in the construction industry in developing countries are obviously more expensive (IBS Roadmap Review, 2007). Hence many contractors are reluctant to adopt the IBS systemand prefer to continue using the conventional method of construction. Based on the research were conducted byRahman\& Omar (2006), financial issueis the main obstacle for construction companies to move forward with the IBS system.

The developing IBS methodin the construction industry in the developing countries is related to the situation of demand for construction. According to survey conducted byThanoon (2003) in the Malaysia, construction companies do not desire construct building with IBS method, due to problems such as:

- Housing demand

- High interest rate

- Unsure economic condition

The government has an important role in developing IBS in Iran. Based on the research conducted byJamshidiyan (2006), the government needs to support the construction industry with paying financial incentive in order to reduce the extra cost of material, and machinery. The government needs also invite construction labor to thetraining course in order to improve the quality of building. Also the other studies show that, most of the labors have the low levels of education (Tabassiet al, 2009).Thelack of knowledge among the architectures who worked in the design group lead to project finished with delay. Hence familiarity with IBS method will facilitate design approval and it is a critical factor to ensure successful IBS project (Construction Industry Master Plan, 2007). Gibb (2001) emphasizes that, to achieve the goals and reduce risk in IBS requires a more coherent structure of process planning and control from start to end of the project is required.

\section{IBS CLASSIFICATION}

IBS is classified based on building materials and the systems of constructing. There are many classificationsof IBS, but Majzubclassification is the most popular classification about IBS.

Table.2 Majzubclassification

\begin{tabular}{lll}
\hline \multicolumn{1}{c}{ General System } & \multicolumn{1}{c}{ System } & \multicolumn{1}{c}{ Production Material } \\
\hline \multirow{3}{*}{ Frame Systems } & $\begin{array}{l}\text { Light Frame } \\
\text { Medium Light Frame }\end{array}$ & $\begin{array}{l}\text { Wood, large light gage metals } \\
\text { Metal, reinforced plastics, } \\
\end{array}$ \\
& $\begin{array}{l}\text { Heavy Frame } \\
\text { laminated woodHeavy steel, } \\
\text { concrete }\end{array}$ \\
\cline { 2 - 3 } Panel Systems & $\begin{array}{l}\text { Light and Medium Weight Panel } \\
\text { Heavy Panel (Factory Produced) }\end{array}$ & $\begin{array}{l}\text { Wood frame, metal frame (light } \\
\text { gage) composite materials }\end{array}$ \\
& Heavy Panel (Produced On Site) & Concrete \\
\hline
\end{tabular}

WWw.iosrjournals.org 


\begin{tabular}{lll}
\hline & Medium Weight Box (Mobile) & Wood frame, light gage metal \\
& Medium Weight Box (Sectional) & composite materials \\
Box Systems (Modules) & Heavy Box (Factory Produced) & Wood frame, light gage metal \\
& Heavy Box (Tunnel Produced On & composite materials \\
& Site) & Concrete \\
\hline
\end{tabular}

Source: Kamar, A.M.K (2011), Industrialized Building System (IBS): The Issue of Definition and Classification in IBS towards Open System in Malaysia, International Islamic University Malaysia (IIUM) Press.

\section{REMOVE BARRIERS TO IMPLEMENTATION IBS METHOD IN CONSTRUCTIONS}

There are many barriers in front of developing IBS method in construction industry therefore, for improving and developing IBS method in the countries, the governmentshould find the barriers in order to analyze and find the best solution for solving it. Figure1 shows the most important barriers such as:

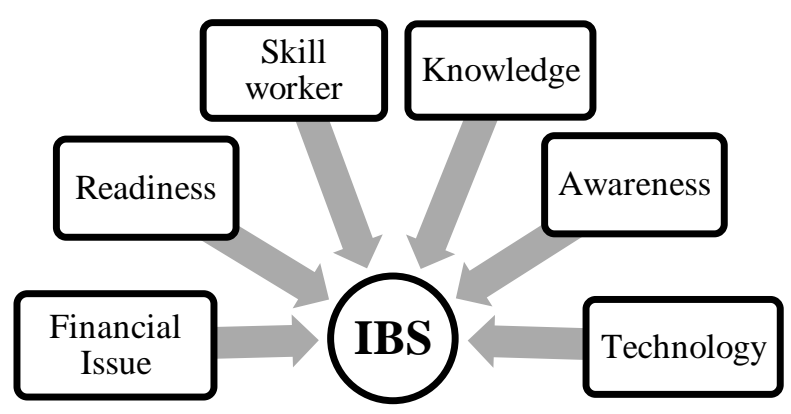

Figure1. Barriers to Industrialized Building System

\section{METHODOLOGY}

To collect data for this study, a questionnaire survey was conducted among the construction companies in Iran. A total of 827 questionnaires were sent out through mail and 117 of them have been received. The respondent rate was $14.1 \%$ for this study. The main aims of this study are to find out the benefits and problems of applying IBS in construction projects, to identify the easiness of IBS usage for construction companies, to explore the level of usefulness of IBS for Iranian construction companies and finally the recommend some solutions to promote IBS concept in construction industry especially in developing countries.

To achieve accurate data, a standard questionnaire was used for this study (Taksiahet al, 2011). The questionnaire involved 4 sections. Parts A and B are going to find out the potential benefits and the problems of applying IBS in the construction projects from the professionals' point of view. By understanding the benefits and problems, it would be easier to explore why IBS concept is not applied in construction projects vastly in Iran. Section $\mathrm{C}$ focuses on, how easy Iranian construction companies can apply IBS concept in their projects. The fourth section is going to find out that how IBS concept is useful and critical for project's success. Reliability statistics used in this research is Cronbach alpha. It is defined as determining the internal consistency or average correlation of items in a survey instrument to gauge its reliability (Cronbach, 1951). Cronbach alpha can be written as a function of the number of test items and the average inter-correlation between the items (Bruin, 2006).

The formula of Cronbach alpha:

$\mathrm{N}=$ number of items

$$
\alpha=\frac{\mathrm{N}^{-} \mathrm{C}}{\mathrm{v}+(\mathrm{n}-1) \cdot{ }^{-} \mathrm{C}}
$$

${ }^{-} C=$ average inter-item covariance among the items

$-\mathrm{v}=$ average variance

The reliability of each part of the questionnaire was investigated to ensure that date is reliable. ( $\alpha$-Cronbach) is between 0 and 1. If ( $\alpha$-Cronbach) is less than 0.5 data are not reliable, therefore the results which were gained through the data analysis are not applicable. In opposite, when ( $\alpha$-Cronbach) is near 1 data is reliable. The mean of ( $\alpha$-Cronbach) for this study is 0.782 and changes the result into one decimal point that will be approximately 0.8 which is considered as reliable. The results achieved through the SPSS software version 19 . 


\begin{tabular}{lcc}
\multicolumn{2}{c}{ Part } & Table3. $\alpha$-Cronbach \\
\hline Benefits of IBS & $\boldsymbol{\alpha}$-Cronbach \\
Problems of IBS & 0.821 \\
Easiness of use IBS & 0.786 \\
Perceived IBS usefulness & 0.834 \\
Mean & 0.688 \\
\hline
\end{tabular}

\section{ANALYSIS \\ VII. I PART A: BENEFITS OF IBS}

Table 4 shows that, most of the construction companies believe that minimal wastage is the most important IBS benefits, because in the conventional method the waste of materials is extremely high in Iran.Therefore IBS concept provided opportunities for companies to reduce the raw material waste in their projects and save material expenses as well. In the IBS method, major parts of the building had produced in the factories and transferred to the construction site. It will lead to less dumped materials in the site and clear work environment. As most of the projects are located in the cities and residential area therefore construction companies prefer to use IBS in order to minimize environmental impacts and pollutions to avoid any conflicts with neighbors or authorities. Another perceived IBS benefit is better control on the products quality. Industrial productions provide the opportunity to produce final product in a controlled environment with minimum chance of human mistake. Therefore building components meet higher quality. In the current competitive market, companies who build buildings with better quality and ensure the quality of components will take over their competitors easily, thus IBS can be an effective method to achieve this goal as well. According to Tabassiet al (2009), Iran construction industry suffers of a large amount of unskilled labor. This condition mostly leads to high rate of human errors, high cost and low quality of buildings. The IBS conceptby transferring most of construction activities from the site to factories can reduce the number of site labors. It not only reduces human costs of project for companies and increase productivity but also lets companies concentrate more on training their limited worker and increase their skills and productivity.

Table4.Descriptive Statistics 1

\begin{tabular}{lccc}
\hline \multicolumn{1}{c}{ Item } & N & Sum & Mean \\
\hline Reduction of site labour & 117 & 456 & 3.90 \\
Minimal wastage & 117 & 484 & 4.14 \\
Less site materials & 117 & 461 & 3.94 \\
Cleaner environment & 117 & 469 & 4.01 \\
Controlled quality & 117 & 462 & 3.95 \\
Neater and safer construction sites & 117 & 445 & 3.80 \\
Faster project completion & 117 & 450 & 3.85 \\
Lower total construction costs & 117 & 449 & 3.84 \\
Valid N (list wise) & 117 & & \\
\hline
\end{tabular}

\section{II PART B: IBS PROBLEMS}

Lack of skill and knowledge on IBS is the main problem that construction companies confront when they planned to implement the IBS method in their projects. Other studies cited this issue as the main hinder of IBS implementation in other parts of the world as well (Hamzahet al, 2010). Lack of expertise can cause of time and cost overrun in the projects that IBS has been applied without appropriate study during the planning phase. As IBS concept is a new construction method in Iran, most of designers and contractors do not have reputation in this field.In addition they do not have access to training courses. Therefore lack of knowledge and expertise is another problem that construction companies have faced with it during using IBS in their projects. This study found out that, IBS is costly for construction companies compared to conventional construction methods. This result is the same with Rahman\& Omar (2006) and Bing (2001) mentioned that higher cost was the main obstacle of using IBS for construction companies. Higher cost mostly resulted from lack of expertise, lack of technologies, lack of standards and government incentives as well as limited suppliers. Another commonbarrieris design alteration during or after construction. Design changes are always costly even in the conventional method, but it depends on in which phase of project change occurs. In the IBS method, because components are produced in factories in large amounts, any design alternations would be extremely costly. Then applying IBS needs the careful design process and several controlling processes before the construction phase to ensure there is no mistake and minimize the chance of any changes after the design phase (Gibb, 2001). 
The Implementation of Industrialized Building System (IBS) in Iran Construction Companies

\begin{tabular}{lccc}
\multicolumn{4}{c}{ Table5. Descriptive Statistics 2 } \\
\multicolumn{1}{c}{ Item } & N & Sum & Mean \\
\hline $\begin{array}{l}\text { Higher cost compared to the } \\
\text { conventional methods }\end{array}$ & 117 & 450 & 3.85 \\
$\begin{array}{l}\text { Complaint on leakage at joints by clients } \\
\text { Lack of expertise in implementation and }\end{array}$ & 117 & 411 & 3.51 \\
$\begin{array}{l}\text { installation } \\
\text { Non acceptance by client }\end{array}$ & 117 & 470 & 4.02 \\
$\begin{array}{l}\text { Problems in design alteration during or } \\
\text { after construction }\end{array}$ & 117 & 448 & 3.61 \\
$\begin{array}{l}\text { Limited suppliers of prefabricated } \\
\text { elements }\end{array}$ & 117 & 444 & 3.83 \\
$\begin{array}{l}\text { Lack of standardization and Repetition } \\
\text { Preference of conventional type of }\end{array}$ & 117 & 395 & 3.79 \\
construction method & 117 & 389 & 3.32 \\
\hline
\end{tabular}

\section{III PART C: EASINESS OF IBS USAGE FOR CONSTRUCTION COMPANIES}

As IBS is the new concept in Iran, hence it is important to find out that construction companies are able to adopt themselves and their companies' culture with this method of construction. If companies cannot apply IBS easily, it would be a serious challenge for them to remain in this competitive field. According to the results, applying IBS concept in the construction projects is not easy for most of construction firms in Iran. They suffer from lack of knowledge and appropriate training about IBS. The majority of respondents stated that even they are willing to use the IBS in their projects; there are not available and trustful data resources in this field. Therefore it would be challenging or in some cases impossible for companies to be skillful in terms of using IBS. In addition, success in IBS projects is related tothe trustful transportation system and needs better logistic practice. Unfortunately on time delivery by transportation system in Iran especially road and railway system is the obstacle for companies to use IBS widely. All these factors proof that transforming from conventional method to IBS and become knowledgeable and skillful in this new concept is extremely hard for Iranian construction companies.

Table6. Descriptive Statistics 3

\begin{tabular}{lccc}
\hline \multicolumn{1}{c}{ Item } & N & Sum & Mean \\
\hline Learning the concept of IBS is easy for the company & 117 & 197 & 1.68 \\
It is easy for the company to become skilful at using IBS & 117 & 238 & 2.03 \\
The transportation and storage of IBS component to be manageable & 117 & 230 & 1.97 \\
The installation of IBS components will require fewer workforce & 117 & 218 & 1.86 \\
It is easy for a company to get info on IBS & 117 & 256 & 2.19 \\
\hline
\end{tabular}

\section{IV PART D: PERCEIVED IBS USEFULNESS}

This section gives response on the perceived IBS usefulness among construction companies. According to the results, perceived IBS usefulness among Iranian construction firm is slightly higher than moderate (average mean 3.31). It means that most of companies do not believe that the IBS can be helpful in their projects. This perception can be considered as the main obstacles for promoting IBS in construction field. Respondents stated that, applying IBS would make it easier to complete a project. Because it lets them have more control on all parts of projects and schedule it more efficient.

Table7. Descriptive Statistics 4

\begin{tabular}{lccc}
\hline & N & Sum & Mean \\
\hline Using IBS in a project would enable the company to & 117 & 332 & 2.84 \\
accomplish construction works more quickly & & & \\
Using IBS would improve project performance & 117 & 375 & 3.21 \\
Using IBS in the project is the way to move forward & 117 & 380 & 3.25 \\
and be more competitive in the construction industry & & & \\
Using IBS would enhance project efficiency & 117 & 423 & 3.62 \\
Using IBS would make it easier to complete a project & 117 & 428 & 3.66 \\
IBS is useful in construction projects & 117 & 388 & 3.32 \\
\hline \multicolumn{1}{l}{ Average Mean } & & & 3.31 \\
\hline
\end{tabular}




\section{CONCLUSION}

As IBS concept is new in Iran, therefore the level of IBS usage is still low and construction companies are not willing to use it. In addition lack of standards and building code in this field is another factor that makes IBS not attractive for construction companies. However awareness on the benefits of IBS among the professionals is high, but the level of implementation of IBS is extremely low in the construction industry in Iran, because of vast obstacles that hinder construction firms to step in. These obstacles are caused by lack of expertise, lack of new technologies and government incentives (Samari, 2012), as well as low completion in this field. Managerial and cultural issue are other factors that stop companies to use IBS in their project, because the companies adopted themselves with conventional method and found it easier for them to complete their projects. In addition their perception on IBS is not positive and they don't look at it as method that can contribute them to project success. To promote IBS among construction companies, it is critical to change their common perception on IBS usefulness before any further actions. In addition there is urgent need to review rules and regulation by government to stimulate IBS among the construction companies.

\section{REFERENCES}

[1] Iran Annual Report, (2008). Continuous flow manufacturing, Material Handling Engineering, Ministry of Housing and Urban Development.May, pp. 54-57Tehran: MHUD, 840.

[2] Kamar, K. A. M., Alshawi, M., And Hamid, Z., (2009).Barriers to Industrialized Building Systems: The Case of Malaysia, paper proceedings inInternational Postgraduate Research Conference (IPGRC 2009), The University of Salford, 29- 30th January. Salford, United Kingdom.

[3] Chung, L. P. and Kadir, A. M., (2007) Implementation Strategy for Industrialized Building System. PhD thesis, UniversitiTeknologi Malaysia (UTM), Johor Bahru.

[4] Lessing, J., Ekholm, A., AndStehn, L.2005, Industrialized Housing-Definition and Categorization of the Concept, 13th International Group for Lean Construction, Sydney, Australia.

[5] Peng, C. S., (1986). The scenario of industrialized building systems in Malaysia.Proceedings of a UNESCO/FEISEAP Regional workshop.UPM, Serdang.

[6] Bing, L., Kwong, Y.W., and Hao, K.J. (2001), Seismicbehavior of connection between precast concrete beams. CSE Research Bulletin, No.14.

[7] Warszawski, A., (1999). Industrialized and automated building systems.Technion Israel Institute of Technology. E \& FN Spon.

[8] Zaini, O., (2000). Malaysian Construction Industry. Challenges and demand. Malaysian Structural Steel Association Convention, Kuala Lumpur.

[9] Thanoon, W. A. M., Peng, L. W., Abdul Kadir, M. R., Jaafar, M.S. and Salit, M.S., (2003). The Experiences of Malaysia and Other Countries in Industrialized Building System in Malaysia, Proceeding on IBS Seminar. UPM, Malaysia.

[10] IBS Steering Committee, (2006). Minute Meeting of IBS Steering Committee, Construction Indu stry Development Board (CIDB) Malaysia, Kuala Lumpur.

[11] Rahman, A. B. A., Omar, W., (2006). Issues and Challenge in the Implementation of IBS in Malaysia, Proceeding of the 6th Asia Pacific Structural Engineering and Construction Conference (ASPEC 2006), 5-6 September 2006. Kuala Lumpur, Malaysia.

[12] Hamid, Z., Kamar, K. A. M., Zain, M., Ghani, K., Rahim, A. H. A. (2008) Industrialized Building System (IBS) in Malaysia: the current state and R\&D initiatives, Malaysia Construction Research journal, Vol. 2 (1), pp 1-13.

[13] IBS Roadmap Review, (Final Report) (2007), IBS Centre, Construction Industry Development Board, Malaysia, Kuala Lumpur.

[14] Jamshidiyan, A., (2006), Construction Problems in Iran, Challenges and demand. The civil engineering conference.Mahabad University, Iran.

[15] Tabassi, A. A., Abu Bakar. A. H., (2009). Training, motivation, and performance: The case of human resource management in construction projects in Mashhad, Iran International Journal of Project Management 27, 471-480.

[16] CIMP (2007) Construction Industry Master Plan 2006 - 2015 (CIMP 2006 - 2015), Construction Industry Development Board Malaysia (CIDB), December 2007, Kuala Lumpur.

[17] Gibb, A., (2001). Pre-assembly in construction: A review of recent and current industry and research initiatives on pre-assembly in construction, CRISP Consultancy Commission (00/19), May 2001.

[18] Majzub, (1977). Modular housing systems used around the world. International Journal of Housing Science, Vol.1.

[19] Taksiah, A. M., Azmani. A., Zakaria, S. A., Yahya, S.A., Zaini, S., Sanusi, M., Hanafi, H. M., (2011). Quantitative Analysis on the Level of IBS Acceptance in the Malaysian Constructions Industry. Journal of Engineering Science and Technology, Vol. 6, No. 2 (2011) $179-190$

[20] Cronbach, L. J. (1951). Coefficient alpha and the internal structure of tests.Psychometrika, 16, $297-334$.

[21] Hamzah.H.N.,Nafi, A. N. M.,Yacob, J., Shari, H. A., Daud, Z., Sharkawi, A. , (2010).A Study on the Acceptance of IBS in Construction Industry in Kelantan: Application of Logistic Regression Analysis, Proceedings of the Regional Conference on Statistical Sciences (RCSS10).

[22] Samari, M., (2012). Sustainable Development in Iran: a Case Study of Implementation of Sustainable Factors in Housing Development in Iran. IPEDR, Vol. 37. ACSITPress, Singapore. 